\title{
Study of the interpopulational variability of the anatomically modern man: interest in orthodontics
}

\author{
L.Q. Pham¹, M. Naaim², M. Makaremi ${ }^{3}$ \\ 1 Dentofacial Orthopedics Department, College of Odontostomatology, University of Medicine \\ and Pharmacy, Ho Chi Minh City \\ 2 University of Bordeaux \\ ${ }^{3}$ Qualified specialist in Dentofacial Orthopedics, Private Practice, Head of Research \\ in Anthropology
}

SUMMARY

Whatever our origins, we are all directly linked by our common ancestors. The brief period that separated the birth of different populations of Homo sapiens that inhabit the Earth explains the homogeneity of the craniofacial architecture of our species. However, some differences to the face show significant interpopulational variations. This is true in the case of dental maturity and the position of the lower incisors, two particularly important factors that mold our orthodontic analysis. This article proposes to do a synthesis of the interpopulational variability of these two parameters.

\section{KEYWORDS}

Ethnic factor, variability, dental maturity, position of the lower incisors

In 2015, in a world that opens up and becomes more globalized every day, as that does not surprise us at all, we may have to develop therapeutic strategies for our four patients from different populations (Fig. 1).

The integration of the ethnic factor at its appropriate value in the analysis matrix that guides our choice of treatment therefore becomes a daily dilemma.

To assigned it a misplaced importance or to ignore the ethnic factor may distort our therapeutic choices.
First of all, once we become interested in the concept of variability in anatomically modern humans, it is important to keep in mind that many studies have shown that the entire human population on Earth has as common ancestors, a small group of some dozens of people living in Africa approximately 100,000 years ago (Fig. 2). At the evolutionary level, that is a relatively short time that has not been able to provide sufficient time for the craniofacial architecture to present a significant difference between the different human 
populations. Whatever our physical appearance, we must be aware of the uniqueness of the human species.

However, the facial morphology is one of the areas where interpopulational variability is most prominently manifested. The morphology of the face is an important selection criterion in the choice of partners, as cultural relevance in beauty perception can generate a natural selection of certain anatomical traits within populations. Moreover, facial growth is subject to environmental factors, as it can vary based on geographic areas.

This article addresses the interpopulation variability of two parameters that are decisive in our choice of treatment; i.e., the position of the lower incisor and dental maturation.

The goal is to summarize several studies that establish a standard for one of these two variables, for a given population. It will provide support in our clinical practice and will similarly showcase how anthropology can be helpful in our daily practice.
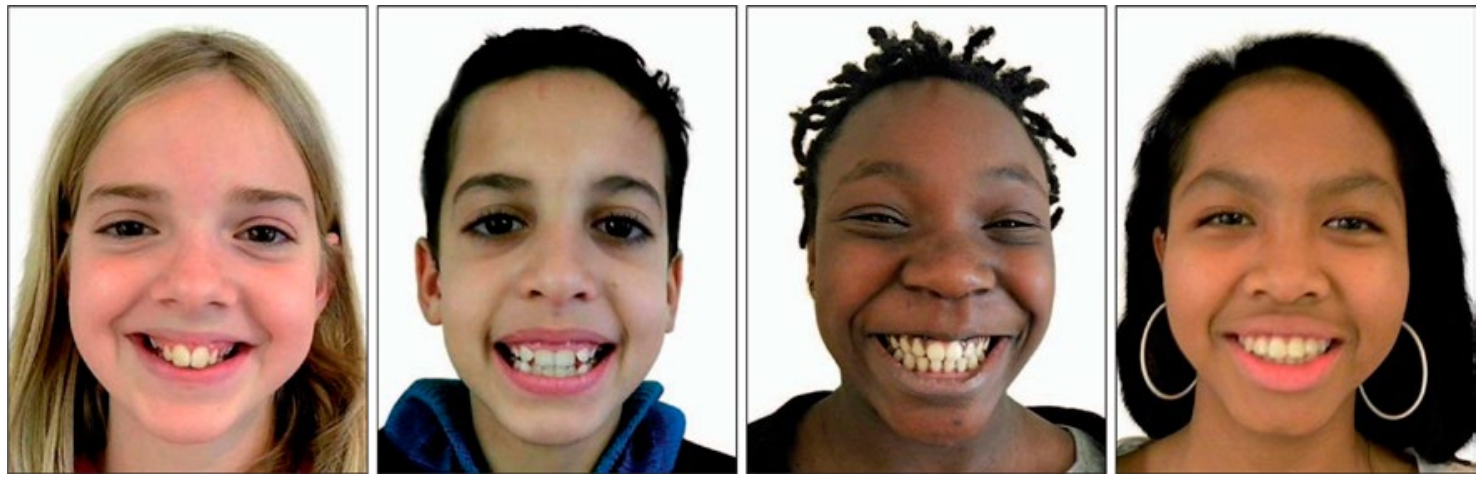

Figure 1
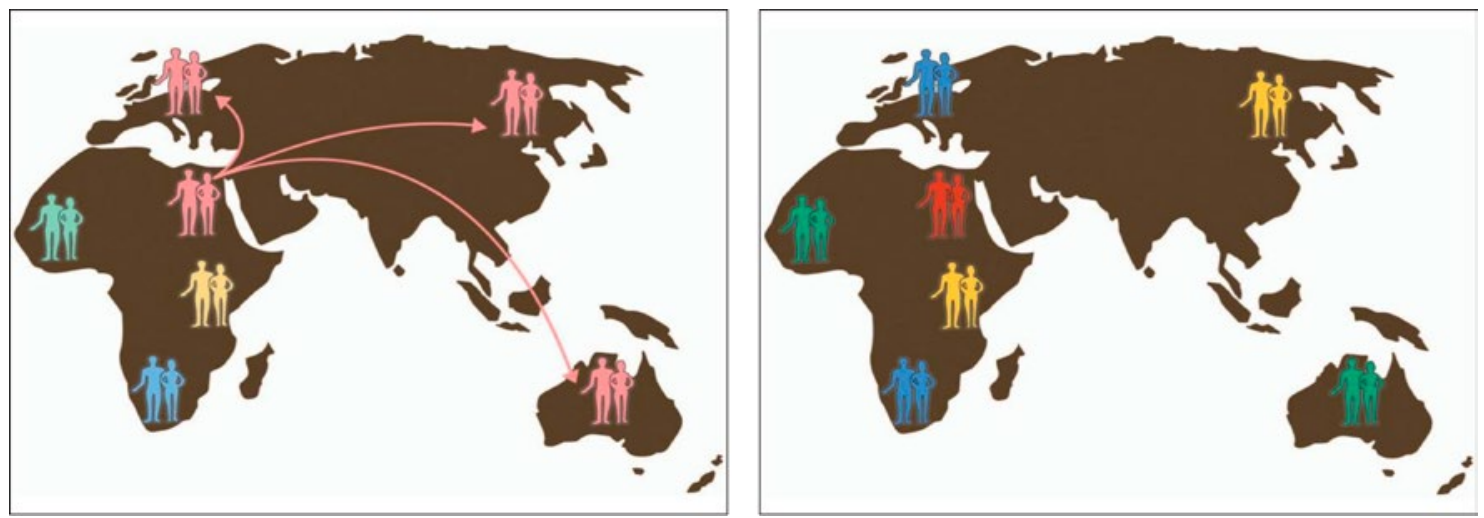

Map 1 Map 2

Figure 2

Map 1: 100,000 years: individuals of an African population migrate to Eurasia and Australia. Map 2: 100,000 years - present: the scattered human populations diverge. (According to Boyd and Silk). 


\section{INTERPOPULATIONAL VARIABILITY OF THE LOWER INCISOR POSITION}

The position of the lower incisor is recognized as one of the most important cephalometric standards to define diagnosis in the anteriorposterior sense and to guide orthodontic treatment. It determines the diagnosis of alveolar protrusion or retrusion; it justifies or refutes indications of extraction or even orthognathic surgery in cases of significant alveolar compensation, in order to regain both dentoskeletal balance and facial esthetics with good lip profile support. On the other hand, this so-called ideal position of the lower incisor with an inter-incisive angle and an appropriate anterior guidance ensures the stability of the treatment and the correct functioning of the masticatory apparatus, avoiding the recurrence of supraocclusion as well as the longterm stability of the incisors.

\section{Measurement Methods}

In the cephalometric analysis, the positioning of the lower incisor may be determined by several angular measurements such as the axis of the incisor in relation to the skull base, Z-angle, i-centroidcondy-link, functional occlusal i-plane, i/NB, IMAP, i/GoGn, and the linear ones, such as i-NB, i-APog (Fig. 3).

It is important to distinguish between two parameters: the relationship between the ideal position of the lower incisor and its influence on facial esthetics, a perception subject to cultural influence, and the reality of the anatomical position of the lower incisor in the population. This article focuses on this second concept.

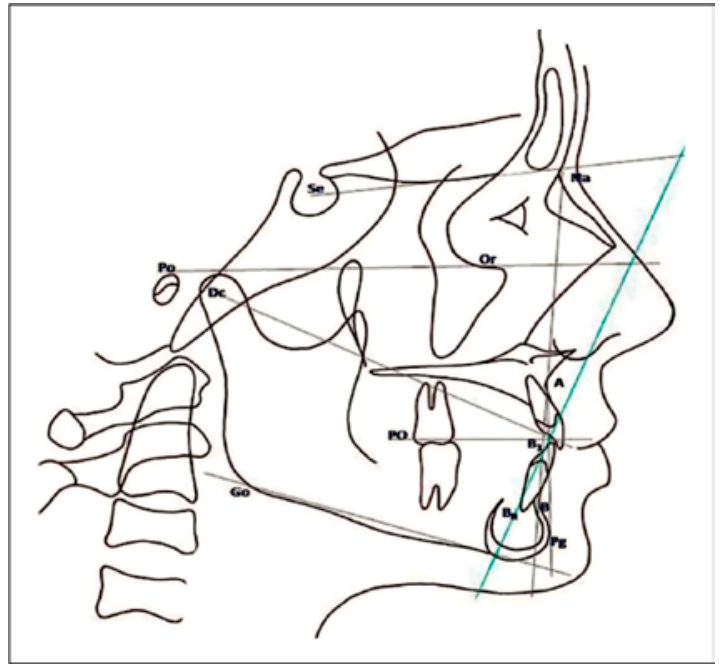

Figure 3

Cephalometric assessment measurement of lower incisor positioning.

Most studies on populations of different ethnic origins have determined average values, whether IMPA or $\mathrm{i} / \mathrm{GoGn}$, reinforced by $\mathrm{i} / \mathrm{NB}$, in some studies. These average values are various and difficult to remember. That is why, pursuant to the summary table with the results of the studies (Fig. 4), we offer a map of the world, with rounded figures, which may serve as clinical memorandum for orthodontists (Fig. 5).

In general, there is no significant difference between genders.

\section{Classification and discussion}

The inexhaustive results of literature review results we have collected are classified herein by growing incisive inclination tilt.

The Bangladeshi population presents the smaller i/MP angle, at $92^{\circ}$, more or less equal to that of Caucasians (Europeans, white Americans) 


\begin{tabular}{|c|c|c|c|c|}
\hline Studies & Population & $\begin{array}{c}\mathrm{i} / \mathrm{NB}(\mathrm{o}) \\
\text { Women/Men }\end{array}$ & $\begin{array}{l}\text { i-to-NB } \\
(\mathrm{mm}) \\
\text { Woman/Man }\end{array}$ & $\begin{array}{c}\text { i/MP (o) } \\
\text { Woman/Man }\end{array}$ \\
\hline Connor - Moshiri12 & African-American & & & 98.12 \\
\hline Dandajena - Nanda 12 & Africa & 37.6 & 10.3 & 105.8 \\
\hline Stahl de Castrillon13 & Germany & $22.9 / 24.9$ & $3.9 / 4.4$ & $94.1 / 92.3$ \\
\hline Riedel 8 & USA & 25 & 5 & 93.09 \\
\hline Alam1 & Bangladeshi & & & $91.13 / 92.24$ \\
\hline Steiner14 & Caucasian & 25 & 4 & \\
\hline Burstone5 & Caucasian & & & 95.9 \\
\hline McNamara6 & Caucasian & & & $96.6 / 92.5$ \\
\hline Cheng 12 & Chinese & & & 95 \\
\hline Fu12 & Chinese & & & 97 \\
\hline $\begin{array}{l}\text { Y junctions } \\
\text { Gu6 }\end{array}$ & Chinese & & & $94.5 / 94.4$ \\
\hline Kim12 & Korean & & & 96.91 \\
\hline Kwang-Won12 & Korean & & & 92.12 \\
\hline Park12 & Korean & 26.7 & 6.9 & \\
\hline Hamdan7 & English & & & 93 \\
\hline Gulati3 & Northern Indian & & & $102.4 / 103$ \\
\hline Singh11 & Northern Indian & & & $97.41 / 92.21$ \\
\hline Alcalde2 & Japanese & & & $94.32 / 95.09$ \\
\hline Chang 12 & Japanese & 29.2 & 7.3 & \\
\hline Iwasawa12 & Japanese & & & 95.5 \\
\hline lizuka et Ishikawa12 & Japanese & & & 96.33 \\
\hline Kobayashi12 & Japanese & 27.5 & 6 & \\
\hline Kayukawa12 & Japanese & & & 95.3 \\
\hline Takano12 & Japanese & 28.5 & 6.5 & \\
\hline Yamauchi 12 & Japanese & & & 96.1 \\
\hline Hamdan7 & Jordan & & & $96.5 / 95.2$ \\
\hline Ousehal 10 & Moroccan & 28.17 & 6.64 & \\
\hline Lahloug & Moroccan & 28.09 & 6.06 & 95.43 \\
\hline Trivedi 15 & Rajasthani & & & $101.66 / 103.49$ \\
\hline Hassans & Western Saudi Arabian & $30.7 / 29.5$ & $7.5 / 7.2$ & $97.5 / 96.6$ \\
\hline Aldrees3 & Saudi Arabian & & & 96.38 \\
\hline Al-Jasser3 & Saudi Arabian & 28.3 & & 96.4 \\
\hline Al-Showial3 & Saudi Arabian & 25.91 & & 97.73 \\
\hline Namankani & Saudi Arabian & 26.96 & & 95.26 \\
\hline Basciftci4 & Turkish & 27.68 & 4.82 & 96.5 \\
\hline
\end{tabular}

Figure 4

Cephalometric standards concerning lower incisor positioning observed in different populations. 


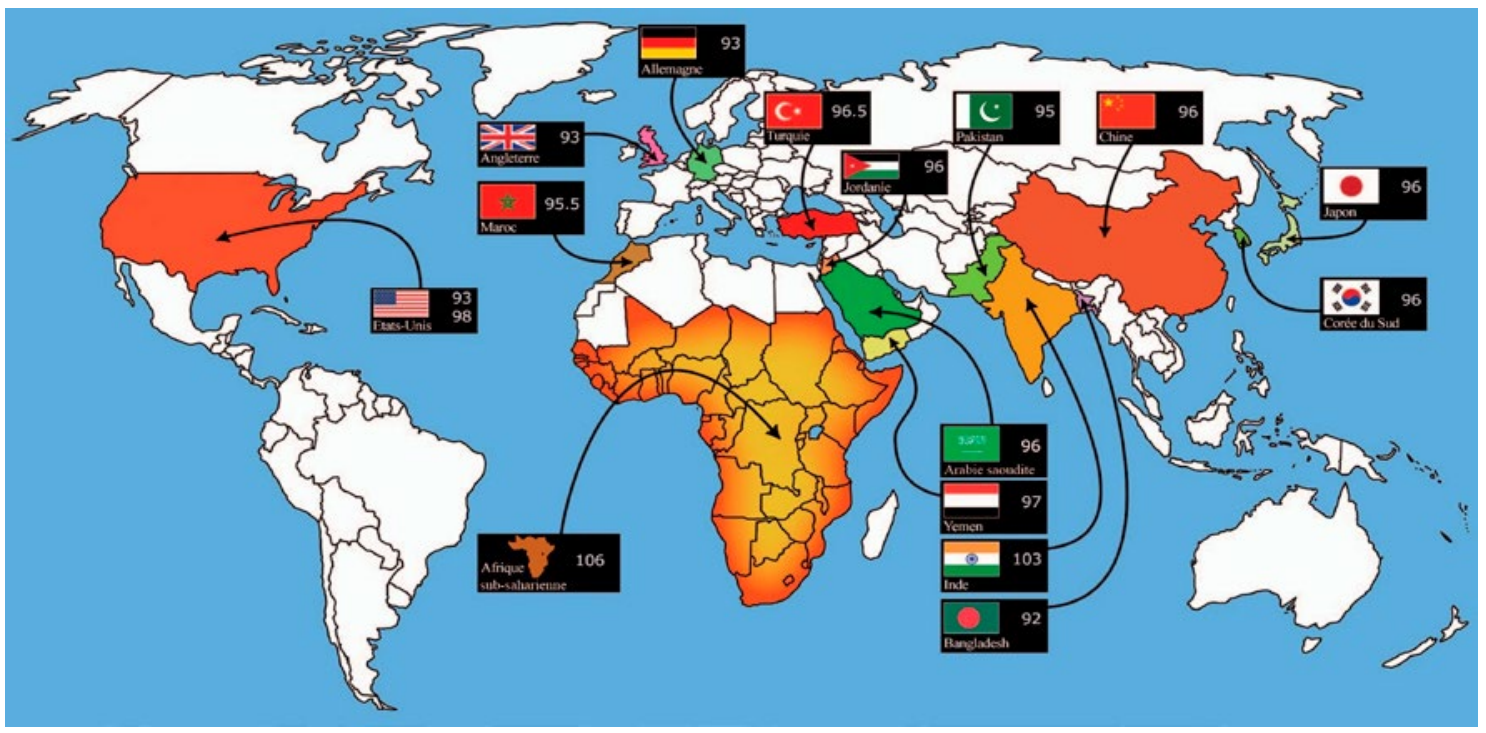

Figure 5

IMPA angle panel in the world.

which is at $93^{\circ}$. This means a somewhat low inclination of the lower incisors in relation to the symphysis. This angle is confirmed by $\mathrm{i} / \mathrm{NB}$, which has a value of approximately $24^{\circ}-25^{\circ}$, showing a position a tad vestibular-bound of these incisors in relation to their base, namely, the mandible. These values are justified in these populations, which generally have a flat subnasal profile, in relation to a nose rather high and a chin that is relatively shallow. The i-NB distance is also the smallest distance among the populations studied, at $4-5 \mathrm{~mm}$.

The populations of Northern India, Northern Africa (Moroccans), the Middle East, Eastern Asia (Chinese, Japanese, Koreans) and the Turks feature an i/MP angle a little more pronounced, at $95^{\circ}-96^{\circ}$. This corresponds to a relatively convex profile with something of an alveolar protrusion, light jaw hypoplasia, and a somewhat stronger chin. The i/NB angle at $26^{\circ}-28^{\circ}$ confirms this tilt, and the i-NB distance is also more pronounced than among Caucasians, approximately 6-7 $\mathrm{mm}$.

Saudi Arabians present an i/MP angle a bit more relevant than in the preceding group, at $97^{\circ}$, as confirmed by the i/NB angle at $30^{\circ}$ and i-NB à $7.5 \mathrm{~mm}$. This can be explained by the geographical proximity to Africa and by a population of mixed origins.

The lower incisors are the most vestibular-bound among African Americans, Indians, and Africans, with average i/MP angle at $98^{\circ}, 103^{\circ}$, and $106^{\circ}$ degrees, respectively. This corresponds to a fairly relevant alveolar protrusion, but which must be considered as "acceptable" in these populations. Alveolar protrusion is confirmed by the i/NB angle and the i/NB distance that likewise have high average values. This relevant, important biprotrusion is in effect one of the anthropometric specificities of people originating from sub-Saharan Africa. The i/NB angle in 
this case can be very high, at $38^{\circ}-41^{\circ}$, with an of i-NB distance at $10 \mathrm{~mm}$.

Orthodontic treatment that considers the specific anatomy of the patient, including the particulars related to their ethnic origins, ensure results that respect patient's individuality and longterm treatment stability.

\section{INTERPOPULATIONAL VARIANCE OF DENTAL MATURATION}

Dental age estimation has different interests: clinical, forensic, and anthropological. In orthodontics, dental maturation is an important factor in choosing the age to begin treatment. It also guides us toward our decisions during treatment: delayed or precocious eruption, ectopic dental eruption, agenesis, extraction choice, transitory DDM upon eruption of lower incisors, and wisdom tooth eruption.

Dental maturation presents a relatively important variation that can be linked to several factors, such as gender, dentomaxillary disharmony, the child's size, warmer or colder weather, socioeconomically conditions, and ethnic factors.

There are different maturation measurement methods, according to the authors $21,22,23,25,29$ : the method by Demirjian 22,23 is frequently employed in orthodontics.

In literature, there are very few studies comparing dental maturation between different ethnic groups. Among these studies, the study by Nils et al. ${ }^{20}$ on 9577 panoramic tomography examinations in eight countries, with the sampling age ranging from 5 to 16 years, is domineering.

Several studies on dental maturation were performed to confirm the relevance of the Demirjian method of different ethnic groups, but with no comparison between them.
We have collected and classified the results of the studies mentioned above, to compare the dental maturation between different ethnic groups.

Most studies find a significant difference between the prediction of the age estimated by the Demirjian method on their population, and the picture by Demirjian ${ }^{22}$ on the FrenchCanadian population.

In order to compare the different studies, we chose similar studies in their methods, and excluded studies following methods other than Demirjian's.

We took the French-Canadian population as our reference and analyzed the differences in dental maturation of each population in relation to the French-Canadian population. We then compared the differences between them. The observed differences are calculated per month. The selected age group samples vary according to the author, between 2 and 18 years of age.

\section{Results and classification}

It is possible to read in the table (Fig. 6) the variability of dental maturation for different countries when compared to the Franco-Canadian population. For a better overview, the same data is reported on a world map (Fig. 7). 
The difference between the most advanced and most delayed results is 12.38 months. We highlight that Turkish children have the earliest dental maturation (10.38 months) and Venezuelan children have the latest maturation (-1.99 months).

In all results, we find that dental maturation in girls is earlier than in boys.

One can notice convergence in dental maturation of some European populations: England, Belgium, Finland, and France However, there is a significant difference between Spain and Sweden, namely, 8.6 months.

In Asia, we see that the differences in dental maturation between countries are more pronounced than in European countries. There are convergent results between Turkey, Pakistan and Saudi Arabia, as well as between Iran, India, South Korea, and China.

The difference is significant between the two groups of Asian countries.

In South America, there is a significant difference between Brazil and Venezuela.

In the table, we note the lack of results for countries in Africa, the United States, and Russia.

Chaillet et al. ${ }^{20}$ have drawn comparisons on three age ranges (5-11 years; 12-16 years; and 5-16 years old) to understand the effect of puberty on dental maturation. They concluded that differences in dental maturation between ethnic groups during the adolescence period are larger than during the juvenile period.

\section{Discussion}

There are two main factors that seem to influence the variability of dental maturation between different ethnic groups: the genetic factor and the environmental factor.

\section{Genetic factor}

The French-Canadian population is a particular case because it is a mixture of ethnic American Natives and European immigrants (colonization between 1932 and 1937) ${ }^{18}$.

The results show a nonsignificant difference between the different populations, the maximum difference being between Turkish children and Venezuelan children, namely, 12.28 months.

The homogeneity of the results in European countries shows the importance of the ethnic role in dental maturation, by taking into account the geographical proximity. The converging results between Iran and India show the same result.

On the other hand, the significant difference between Spain and France, namely 6.6 months, may be because of mixed ethnic influences that took place in the 12th and 13th centuries between North Africa and Spain.

Samples of unknown ethnic origin or mixed ethnicity are difficult to analyze.

The origin of the differences can be understood by studying the dental maturation of each ethnic group separately.

Historical intercontinental migration may explain the approximation in the results of very distant countries.

\section{Environmental factor}

There is a relationship between ecological factors and tooth maturation. The biological adaptation of man in his environment can influence dental maturation. Physical factors such as temperature or humidity can play an important 


\begin{tabular}{|c|c|c|c|c|c|}
\hline Country & Reference & $\begin{array}{l}\text { Average } \\
\text { (months) }\end{array}$ & $\begin{array}{c}\text { Boy } \\
\text { (months) }\end{array}$ & $\begin{array}{c}\text { Girl } \\
\text { (months) }\end{array}$ & $\begin{array}{c}\text { Age } \\
\text { (years) }\end{array}$ \\
\hline Turkey-CAN & Emine Sen Tunc et al., 2007 & +10.38 & +10.68 & +11.64 & $4-12$ \\
\hline Spain-CAN & $\begin{array}{l}\text { Angelines Cruz-Landeira, et al., } \\
2009\end{array}$ & +9.84 & +9.12 & +10.56 & $4-17$ \\
\hline Saudi Arabia-CAN & Ziad D. Baghdadi, 2013 & +8.6 & & & $4-14$ \\
\hline Pakistan-CAN & Rashna H., Sukhia, et al., 2010 & 8.52 & 7.08 & 9.96 & $7-14$ \\
\hline Brazil-CAN & Eid RMR, et al., 2002 & +7.76 & +8.17 & +7.3 & $6-14$ \\
\hline England-CAN & Liversidge HM, et al., 1999 & +7.44 & +8.76 & +6.12 & \\
\hline China-CAN & Chen JW, et al.,2009 & +5.5 & +3.6 & ++7.5 & $8-16$ \\
\hline Australia-CAN & Nils Chaillet, et al., 2005 & +3.48 & & & $5-16$ \\
\hline France-CAN & Nils Chaillet, et al., 2005 & +3.36 & & & $5-16$ \\
\hline Finland-CAN & Nils Chaillet, et al., 2005 & +2.4 & & & $5-16$ \\
\hline Iran-CAN & Ali bagherian, et al.,2011 & +2.16 & +1.8 & +2.52 & $6-13$ \\
\hline $\begin{array}{l}\text { India (Belgaum)- } \\
\text { CAN }\end{array}$ & Hegde RJ, et al., 2002 & +1.8 & +1.68 & +0.48 & $6-13$ \\
\hline Belgium-CAN & Chaillet N., et al., 2005 & 1.68 & & & $5-16$ \\
\hline Sweden-CAN & Chaillet N., et al., 2005 & +1.2 & & & $5-16$ \\
\hline Korea-CAN & Chaillet N., et al., 2005 & -0.12 & & & $5-16$ \\
\hline Venezuela-CAN & $\begin{array}{l}\text { Angelines Cruz-Landeira, et al., } \\
2009\end{array}$ & -1.99 & -2.78 & -1.2 & $2-18$ \\
\hline
\end{tabular}

NB: $($ ) = Overestimation of the Demirjian method; $(-)=$ underestimation of the Demirjian method; CAN = FrenchCanadian; Average = shows the difference in predicted age between French-Canadians and other countries, for example, dental maturity of French children is 3.36 months more advanced compared to dental maturity of FrenchCanadian children.

\section{Figure 6}

Comparison of dental maturity in different countries relative to Canadian children.

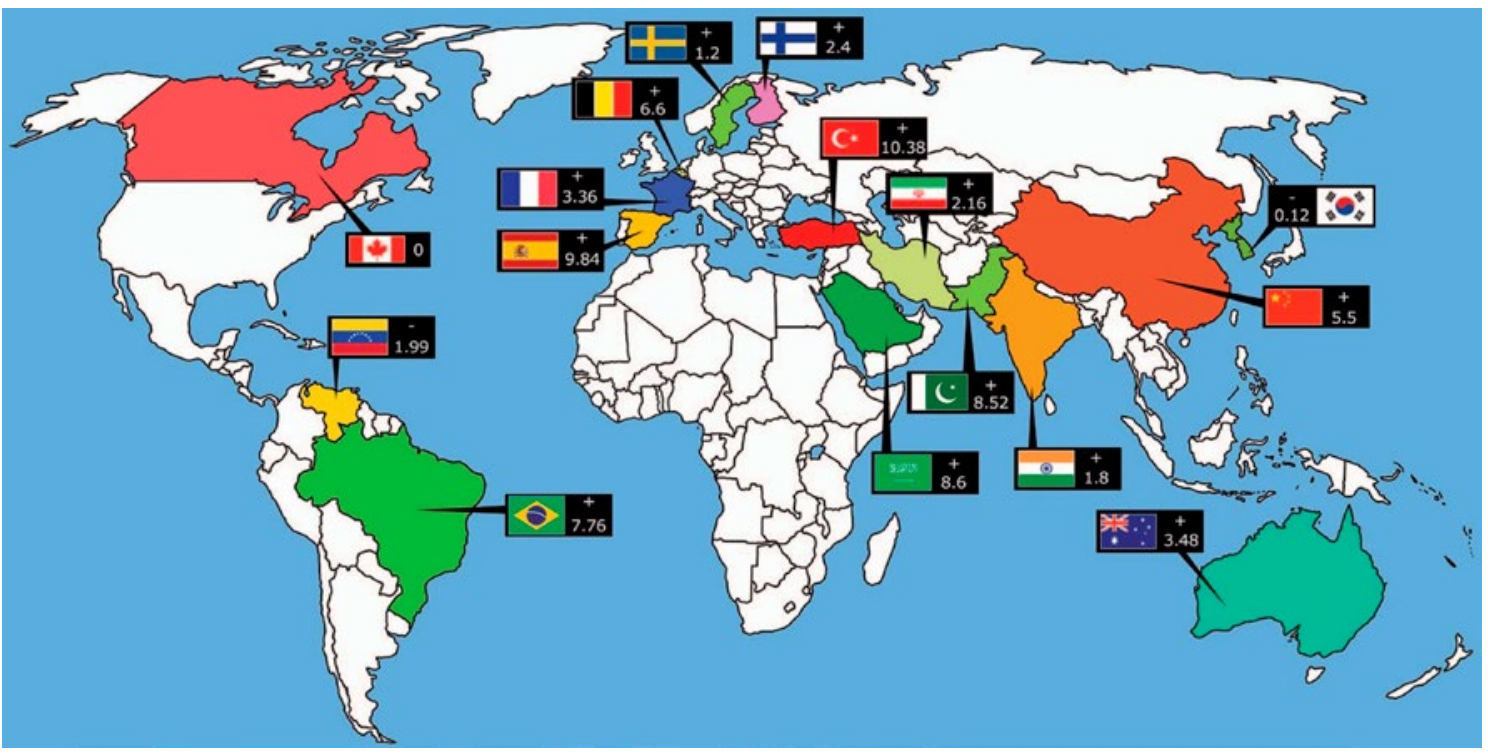

Figure 7

Difference of dental maturation of different populations compared to Canadian children. 
role in growth and dental maturation, which can change human metabolism. One can notice the convergence of results between Sweden and Finland, with a very cold climate, and between Saudi Arabia and Pakistan, with a very warm climate. Presumably, maturation is more advanced in a warmer climate than in a colder climate.

It is very difficult to separate the ethnic factor or other factors, such as weather, biological, social, nutritional, among others, that may influence growth and dental maturation.

According to the authors, the diversity of results is because of several factors: the accuracy of the method, the age, the structure of the sample, the sample size, the statistical approach and the importance of individual biological variation of each child.

The various authors agree on the fact that each population may require

\section{CONCLUSION}

Taking the ethnic factor into account in our treatment decisions is a requirement, because it prevents diagnostic errors and optimizes the individualization of treatment.

However, that is a subtle concept, where one must avoid approximations: for example, the average position of the lower incisor has a difference of $10^{\circ}$ between the Bangladeshi and Indian populations. These two populations cannot be combined when considering that the patient comes from the Indian subcontinent, or when applying Caucasian cephalometric standards.

Taking the ethnic factor into account is otherwise more complex insofar

\begin{tabular}{|c|l|}
\hline Country pairs & Difference \\
\hline France-CAN & 3.36 months \\
\hline Belgium-Sweden & 0.4 months \\
\hline Spain-Sweden & 8.6 months \\
\hline Iran-India & 0.36 months \\
\hline Saudi Arabia-Pakistan & 0.08 months \\
\hline Pakistan-South Korea & 8.64 months \\
\hline China-Korea & 5.62 months \\
\hline Brazil-Venezuela & 9.77 months \\
\hline
\end{tabular}

Figure 8

Examples of differences in dental maturation between countries.

its own specific standard for accurate estimation of the chronological age.

that it requires to distinguish the cultural part from the anatomical reality and to avoid stereotypes.

Ultimately, meta-analyses should allow us to have standardized, comprehensive databases that could help us guide our therapeutic choices for patients from different populations.

In the small village that our Earth has become, facing the variability in different populations in our daily clinical activity is becoming the norm rather than the exception.

Conflict of interest: The authors report no conflict of interest. 


\section{BIBLIOGRAPHY}

\section{Interpopulational variability of the lower incisor position}

1. Alam MK, Basri R, Purmal K, Rahman SA, Shaari A, Haq ME. Cephalometric for Orthognathic Surgery (COGS) for Bangladeshi population. Int Med J 2013; 20(3):345-8.

2. Alcalde RE, Jinno T, Pogrel MA, Matsumura T. Cephalometric norms in Japanese adults. J Oral Maxillofac Surg 1998;56(2):129-34.

3. Aldrees AM. Lateral cephalometric norms for Saudi adults: a meta-analysis. Saudi Dent J 2011;23(1):3-7

4. Basciftci FA, Uysal T, Buyukerkmen A. Craniofacial structure of Anatolian Turkish adults with normal occlusions and well-balanced faces. Am J Orthod Dentofacial Orthop 2004; 125(3):366-72.

5. Gulati R, Jain S. Cephalometric norms for orthognathic surgery for North India (Western Uttar Pradesh). Natl J Maxillofac Surg 2011;2(1):33-7.

6. Gu Y, McNamara JA, Sigler LM, Baccetti T. Comparison of craniofacial characteristics of typical Chinese and young Caucasian adults. Eur J Orthod 2011;33(2):205-11.

7. Hamdan AM, Rock WP. Cephalometric norms in an Arabic population. J Orthod $2001 ; 28(4): 297-300$.

8. Hassan AH. Cephalometric norms for Saudi adults living in western region of Saudi Arabia. Angle Orthod 2006;76(1):109-13.

9. Lahlou K, Bahoum A, Makhoukhi MB, Aalloula el H. Comparison of dentoalveolar protrusion values in Moroccans and other populations. Eur J Orthod 2010;32(4):430-4.

10. Ousehal L, Lazrak L, Chafii A. Cephalometric norms for a Moroccan population. Int Orthod 2012;10(1):122-34.

11. Singh SP, Utreja AK, Jena AK. Cephalometric norms for orthognathic surgery for North Indian population. Contemp Clin Dent 2013;4(4):460-6.

12. Solmaz I, Raberin M. Le facteur ethnique est-il un indicateur thérapeutique? Orthof $\mathrm{Fr}$ 2011:82:347-58.

13. Stahl de Castrillon F, BaccettiT, Franchi L, Grabowski R, Klink-Heckmann U, McNamara JA. Lateral cephalometric standards of German with normal occlusion from 6 to 12 years of age. J Orofac Orthop 2013;74(3):236-56.

14. Steiner CC. The use of cephalometrics as an aid to planning and assessing orthodontic treatment. Am J Orthod 1960;46:721-35.

15. Trivedi K, Singh S, Shivamurthy DM, Doshi J, Shyagali T, Patel B. Analysis of cephalometrics for orthognathic surgery: Determination of norms applicable to Rajasthani population. Natl J Maxillofac Surg 2010;1(2):102-7.

\section{Interpopulational variability of dental maturation}

16. Cruz-Landeira A, Linares-Argote J, Martínez-Rodríguez M, Sol Rodríguez-Calvo M, Otero $\mathrm{XL}$, Concheiro L. Dental age estimation in Spanish and Venezuelan children. Comparison of Demirjian and Chaillet's scores. Int J Legal Med 2010;124:105-12. 
17. Bagherian A, Sadeghi M. Assessment of dental maturity of children aged 3.5 to 13.5 years using the Demirjian method in an Iranian population. J Oral Science 2011;53(1):37-42.

18. Barret R. Le plan Vautrin et l'abitibi-Témiscamingue, dans I'Abitibi et le témiscamingue, hier et aujourd'hui. Rouyn, Collège du Nord-Ouest, 1975.

19. Chen JW, Guo J, Zhou J, Liu RK, Chen TT, Zou SJ. Assessment of dental maturity of western Chinese children using Demirjian's method. Forensic Sci Int 2010;197:119.e1-119.e4.

20. Chaillet N, Nyström M, Demirjian A. Comparison of dental maturity in children of different ethnic origins: international maturity curves for clinicians. J Forensic Sci 2005;50(5):1164-74.

21. Moorrees CF, Fanning EA, Hunt EE Jr. Formation and resorption of three deciduous teeth in children. Am J Phys Anthropol 1963;21:205-13.

22. Demirjian A, Goldstein $H$. New systems for dental maturity based on seven and four teeth. Ann Hum Biol 1976;3:411-21.

23. Demirjian A, Goldstein $H$, Tanner JM. Human biology. A new system of dental age assessment. Hum Biol 1973;45(2):211-27.

24. Eid RM, Simi R, Friggi MN, Fisberg M. Ltd Assessment of dental maturity of Brazilian children aged 6 to 14 years using Demirjian's method. Int J Paediatr Dent 2002;12:423-8.

25. Harris EF, Buck AL. Tooth Mineralization: A Technical Note on the Moorrees-Fanning-Hunt Standards. Dental Anthropology 2002;16(1).

26. Tunc ES, Koyuturk AE. Dental age assessment using Demirjian's method on northern Turkish children. Forensic Sci Int 2008;175:23-6.

27. Liversidge HM. Similarity in dental maturation in two ethnic groups of London children. Ann Hum Biol 2011;38(6):702-15.

28. Hegde RJ, Sood PB. Dental maturity as an indicator of chronological age: radiographic evaluation of dental age in 6 to 13 years children of Belgaum using Demirjian methods. J Indian Soc Pedod Prev Dent 2002;20(4):132-8.

29. Nolla CM. The development of the permanent 16. Holtgrave EA, Kretschmer R, Moller R, 1997teeth. J Dent Child 1960;27:254-66.

30. Sukhia RH, Fida M, Azam SI. Dental age table for a sample of Pakistani children. Eur J Orthod 2012;34:77-82.

31. Baghdadi ZD. Dental maturity of Saudi children: Role of ethnicity in age determination. Imaging Sci Dent 2013;43:267-72. 